\title{
A novel regulatory B-cell population in sheep Peyer's patches spontaneously secretes IL-10 and downregulates TLR9-induced IFN $\alpha$ responses
}

\author{
JS Booth $^{1}$, PJ Griebel ${ }^{1}$, LA Babiuk ${ }^{2}$ and GK Mutwiri ${ }^{1}$
}

Peyer's patches (PPs) play an important role in the induction of immune responses in the intestine, but regulation of Toll-like receptor (TLR)-induced innate immune responses in PPs is not well understood. We investigated the responses of PPs and other immune cells to the TLR9 agonist, CpG oligodeoxynucleotide (ODN). Peripheral blood mononuclear cells and lymph node cells secreted significant amounts of interferon (IFN)- $\alpha$, IFN $\gamma$, and interleukin (IL)-12 following stimulation with $\mathrm{CpG}$ ODN. In contrast, PP cells exhibited poor cytokine responses, despite abundant expression of TLR9 mRNA. PP cells spontaneously secreted high levels of IL-10, and the primary source of the IL-10 was resting CD5 $-C D 11 c^{-} C D 21+B$ cells. Neutralization of the IL-10 or depletion of CD21 + B cells resulted in a significant increase in CpG-induced IFN $\alpha$-response in PPs, suggesting that IL-10 from B cells regulate innate responses in PPs. These IL-10-secreting PP B cells may represent a novel subset of the recently proposed regulatory $B$ cells $\left(B_{\text {regs }}\right)$ in the intestine.

\section{INTRODUCTION}

The innate immune system has an intricate system of receptors called pattern recognition receptors, which have the ability to recognize pathogen-associated molecular patterns (PAMPs) as danger signals. ${ }^{1}$ On recognition of their respective ligands, pattern recognition receptors are capable of inducing a variety of innate immune responses. The Toll-like receptors (TLRs) constitute one such family of pattern recognition receptors and are evolutionary conserved transmembrane glycoproteins molecules. ${ }^{2}$ At least 13 TLRs have been identified in mammals and they appear to detect distinct microbial components. For example, TLR3, TLR4, TLR7/8, and TLR9 recognize double-stranded RNA, lipopolysaccharides, single-stranded RNA/imidazoquinolines, and CpG motifs in bacterial DNA, respectively ${ }^{3-6}$ In bacterial DNA, CpG dinucleotides occur in the expected frequency ( 1 of 16), whereas in vertebrate DNA, this frequency is suppressed (1 of 64). The cytosine in CpG dinucleotides is often methylated in vertebrate DNA. ${ }^{7}$ Thus, the vertebrate immune system has evolved to specifically recognize CpG dinucleotides as a way of detecting the presence of microbial organisms.
Both in vitro and in vivo studies have shown that CpG oligodeoxynucleotide (ODN) are potent activators of the innate immune system in numerous species, including humans, nonhuman primates, mice, cattle, sheep, pigs, horses, dogs, cats, chickens, and fish. ${ }^{8-12}$ However, CpG-specific responses differ from species to species and the differences in responses seem to be related to TLR9 expression in different cell types. For example, in resting human cells, B cells and plasmacytoid dendritic cells (pDCs) are the two cell types that predominantly express TLR9 and are directly activated by CpG ODN. ${ }^{13}$ In contrast, in mice, a wide variety of cell types express TLR9 and are activated directly by CpG ODN, including B lymphocytes, monocytes, macrophages, myeloid dendritic cells, natural killer cells, T-regulatory cells, intestinal and pulmonary epithelia, and even mast cells. ${ }^{14-17}$ All of these cell types express functional TLR9 and this explains why CpG ODN is so potent in mice. TLR9 expression in ruminants has been reported recently ${ }^{18}$ and appears to have an expression pattern similar to that of humans. We recently reported that sheep LN cells respond well to all three classes of CpG ODN and with higher magnitude than peripheral blood mononuclear cells (PBMCs). ${ }^{19}$ However, responses in

\footnotetext{
${ }^{1}$ Vaccine and Infectious Disease Organization/International Vaccine Center, University of Saskatchewan, Saskatoon, Saskatchewan, Canada. ${ }^{2}$ University of Alberta, University Hall, Edmonton, Alberta, Canada. Correspondence: GK Mutwiri (george.mutwiri@usask.ca) 
gut-associated lymphoid tissues to TLR9 ligand stimulation have not been explored in detail.

The intestinal tract is constantly exposed to microbial flora and must have mechanisms in place to prevent unnecessary and potentially damaging immune responses to harmless commensal flora and dietary antigens. Several mechanisms have been proposed, including downregulation of TLR receptor expression in lamina propria macrophages, ${ }^{20}$ lack of innate receptor expression (CD14, Fc $\alpha, F c \gamma, C R 3$, and CR4) in intestinal macrophages ${ }^{21}$ restricted distribution of TLR expression in intestinal epithelial cells, ${ }^{22}$ and modulation of intestinal epithelia cells by commensal microflora. ${ }^{23}$ However, whether such regulation of immune responses occurs in Peyer's patches (PPs) is not fully understood.

Peyer's patches are the primary site where adaptive immune responses are induced in the intestine of ruminants. ${ }^{24}$ Given the role of this tissue in the initiation of immune responses and the importance of TLR in the initiation and development of innate and adaptive immune responses, a detailed understanding of how PP cells respond to TLR agonists would provide insights into the regulation of immune responses in intestine. Contractor et al..$^{25}$ recently reported that murine PP pDCs, unlike splenic pDCs, were incapable of producing interferon (IFN)- $\alpha$ following stimulation with $\mathrm{CpG}$ ODN, presumably due to the suppressive effects of interleukin (IL)-10 in the PP environment. Recently, IL-10-secreting B cells with a regulatory role have been described in murine models of chronic intestinal inflammation. ${ }^{26}$ We report that PP CD $21{ }^{+} \mathrm{B}$ cells isolated from normal intestinal tissue spontaneously secrete IL-10, which in turn suppresses $\mathrm{CpG}$-induced innate responses.

\section{RESULTS}

\section{IFN $\alpha$ and IFN $\gamma$ secretion is reduced in PP cells stimulated with CpG ODN}

We compared IFN responses in ileal PP (IPP), jejunal PPs (JPP), superficial cervical lymph node (scLN), and mesenteric $\mathrm{LN}(\mathrm{mLN})$ cells following stimulation with $2 \mu \mathrm{g} \mathrm{ml}^{-1}$ of $\mathrm{CpG}$ ODN. Both scLN and mLN exhibited IFN $\alpha$ responses that were significantly higher than in both JPP and IPP cells (Figure 1a). The IFN $\alpha$ responses were similar in cells from both JPPs and IPPs (Figure 1a).

Stimulation of scLN and mLN cells with CpG ODN resulted in a significantly higher production (5- to10-fold) of IFN $\gamma$ than cells from either ileal of jejunal PPs (Figure 1b). However, JPP cells produced significantly more IFN $\gamma$ when compared with IPP cells (Figure 1b). Thus CpG-induced IFN $\alpha$ and IFN $\gamma$ secretion by PP cells was significantly reduced compared with LN cells.

We further performed a dose titration experiment using CpG ODN concentrations of $0.66,2.0,6.0$ and $18.0 \mu \mathrm{g} \mathrm{ml}^{-1}$ on cells from all tissues tested above for both IFN $\alpha$ and IFN $\gamma$ and found that the reduced cytokine responses of PP cells are not due to suboptimal CpG ODN concentration (data not shown). Therefore, regardless of the concentration or class of CpG ODN, interferon (IFN $\alpha$ and IFN $\gamma$ ) responses were significantly lower in PP cells compared with cells isolated from LN and blood.
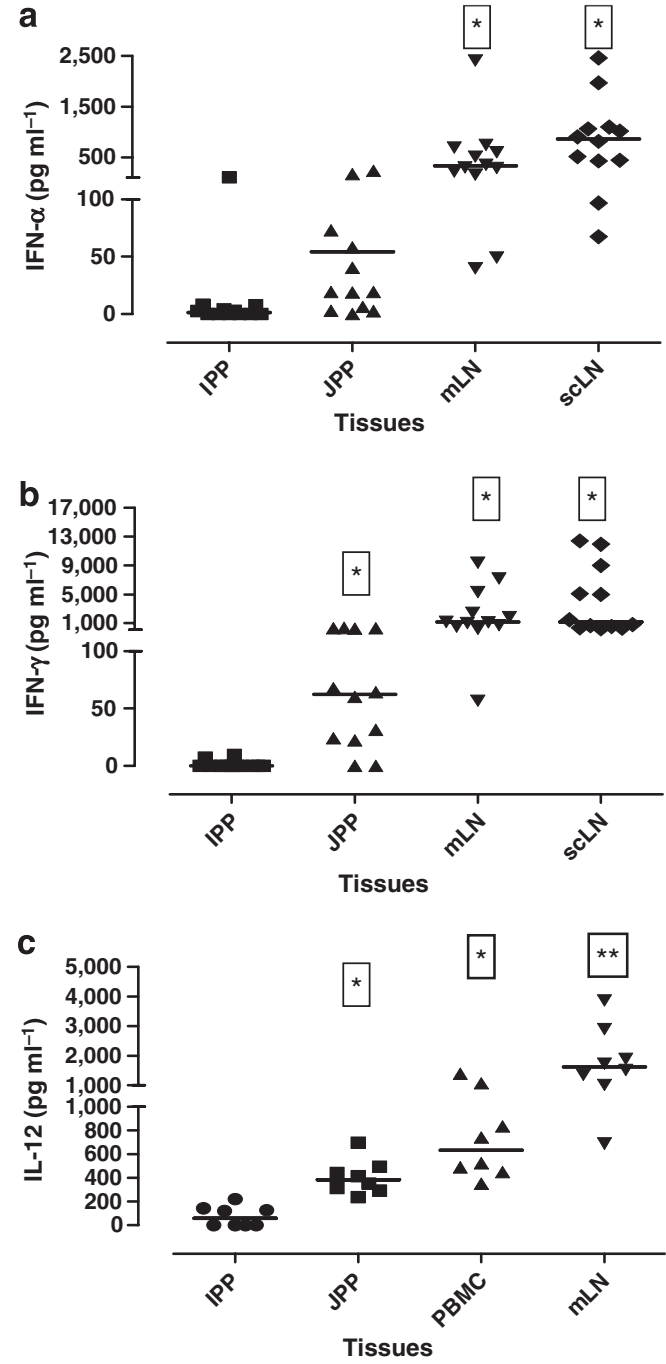

Figure $1 \mathrm{CpG}$-induced IFN secretion in various tissues. (a, b) IFN $\alpha$ and IFN $\gamma$ secretion by ovine IPPs, JPPs and LN cells following stimulation with $2.0 \mu \mathrm{g} \mathrm{ml}^{-1}$ of CpG ODN (2429). Data represent individual values for 12 animals $(n=12)$. Horizontal bar represents mean value for each tissue, and significant difference $(P<0.05)$ relative to ileal PPs are represented by boxed *. (c) IL-12 secretion by ovine IPPs, JPPs, mLN cells and PBMCs following stimulation with CpG ODN 2429 at $2 \mu \mathrm{g} \mathrm{ml}^{-1}$. Data represent the mean value for cells isolated from eight animals. Significant difference $(P<0.05)$ relative to ileal PPs are represented by boxed *. Boxed **indicate significant difference relative to both PP.

\section{IL-12 secretion is reduced in PPs stimulated with CpG ODN}

It was recently reported that $\mathrm{pDC}$ in mouse PPs stimulated with CpG ODN do not produce IFN $\alpha$ but secrete significant amounts of IL- $12 .{ }^{25}$ Therefore, we investigated whether CpG ODN could induce detectable IL-12 secretion in sheep PP cells.

When comparing IL-12 response between the tissues (Figure 1c), CpG ODN induced significantly lower IL-12 secretion in IPP cells compared with cells from the other tissues. Following stimulation by CPG ODN, mLN cells secreted significantly higher levels of IL-12 than PBMC and JPP cells, whereas PBMCs secreted higher levels of IL-12 than JPP cells (Figure 1c). Therefore, IL-12 secretion by PP cells was lower 

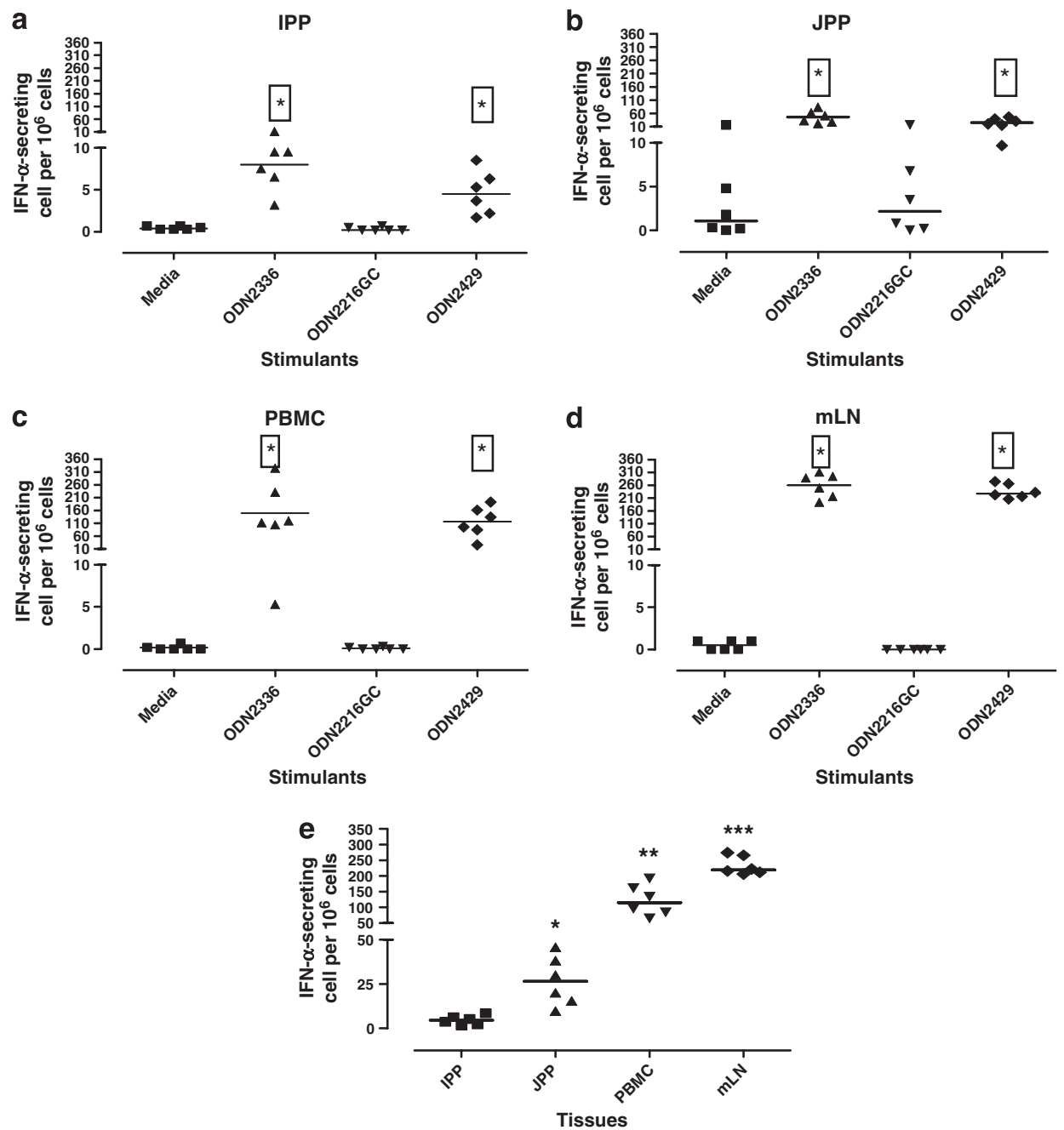

Figure 2 Frequency of IFN $\alpha$-producing cells. (a-d) IFN $\alpha$-producing cell responses in ovine IPPs, JPPs, PBMCs, and mLNs following stimulation with either $2 \mu \mathrm{g} \mathrm{ml}^{-1}$ of CpG ODN 2336; 2429 or $2216 \mathrm{GpC}$ or medium alone. Values from individual animals are presented as mean indicated by horizontal bar for each treatment group $(n=6)$. Significant differences in IFN $\alpha$-producing cells per million cells relative to $\mathrm{GpC}$ controls are indicated by boxed * $(P<0.05)$. (e) Data for individual animals are presented with mean value indicated by horizontal bar for each group $(n=6)$. Significant differences in IFN $\alpha$-producing cells relative to IPP are indicated by * $(P<0.05)$. ** represents significant difference between PBMCs and both PPs, whereas *** represents significant difference between $\mathrm{mLN}$ and all other tissues.

than cells isolated from other tissues and followed a trend similar to the IFN $\alpha$ and IFN $\gamma$ responses.

\section{PPs have a lower frequency of IFN $\alpha$-producing cells}

We hypothesized that the reduced IFN $\alpha$ response in PPs is a consequence of either a lower frequency or a lack of IFN $\alpha$-secreting cells in the tissue. Therefore, we assessed the frequency of IFN $\alpha$ producing cells in the various tissues using an enzyme-linked immunosorbent spot assay.

A significant number of IFN $\alpha$-secreting cells were detected in IPP following stimulation with CpG ODN compared with medium alone (Figure 2a). This response was $\mathrm{CpG}$-specific, as the $\mathrm{GpC}$ control did not induce any detectable responses (Figure 2a). Similarly, a significant number of IFN $\alpha$-secreting cells were detected in JPPs, PBMCs and mLN cells stimulated with CpG ODN (Figure 2b-d). When comparing between tissues, stimulation with $\mathrm{CpG}$ ODN induced a frequency of IFN $\alpha$-secreting cells that was significantly lower in IPP than in all the other tissues (Figure 2e). mLN cells had significantly higher IFN $\alpha$ secreting cells than PBMCs and JPPs, whereas PBMCs had a significantly higher frequency of IFN $\alpha$-secreting cells than JPPs following stimulation with CpG ODN (Figure 2e). Enzymelinked immunosorbent spot assay analysis of the frequency of IFN-secreting cells was consistent with data for enzyme-linked immunosorbent assay analysis of cytokines (Figure 1a).

\section{PPs constitutively express TLR9 mRNA}

We reasoned that IPP and JPP cells may lack sufficient TLR9 expression to respond effectively to CpG ODN stimulation. Therefore, we evaluated TLR9 mRNA expression in cells isolated from different tissues. RNA isolated from IPP, JPP, blood, and $\mathrm{mLN}$ tissue all expressed significant higher copy numbers $(P<0.05)$ of TLR9 than duodenum, jejunum, and colon (Figure 3a). Interestingly, IPP and JPP tissues expressed similar 

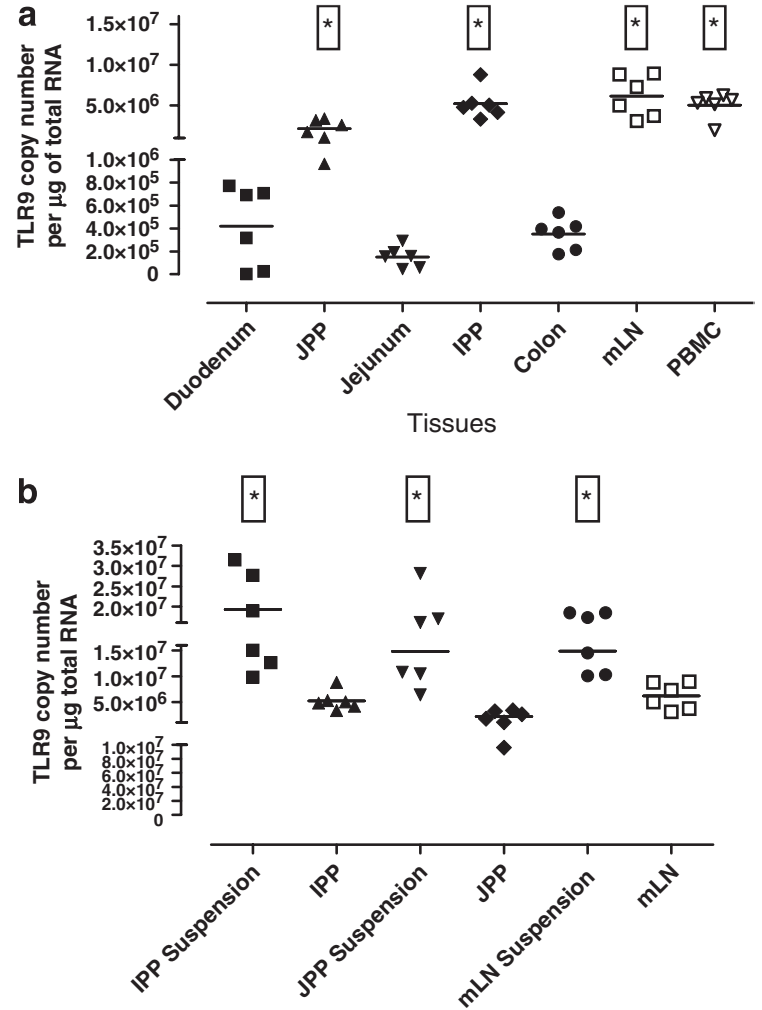

Figure 3 TLR9 mRNA expression in various tissues. (a) TLR9 mRNA expression in ovine IPPs, JPPs, PBMCs, mLNs, duodenum, jejunum, and colon. Data for individual animals are presented, with mean value indicated by horizontal bar for each treatment group $(n=6)$. Significant TLR9 mRNA expression relative to duodenum and colon is indicated by a boxed * $(P<0.05)$. (b) TLR9 mRNA expression in ovine IPPs, JPPs, $\mathrm{mLNs}$, and their respective cell suspension. Data for individual animals are presented, with mean value indicated by horizontal bar for each treatment group $(n=6)$. Significant TLR9 mRNA expression in the cell suspension relative to their respective tissue is indicated by boxed ${ }^{*}(P<0.05)$

levels of TLR9 mRNA as mLNs and PBMCs. As the CpG stimulation experiments were done with cells suspensions rather than in tissues, we wondered whether TLR9 mRNA expression in those cell suspensions differed from that in intact tissues. As shown in Figure 3b, cell suspensions had significantly higher expression of TLR9 mRNA than intact tissues, but the overall pattern of expression was similar. Thus, these data confirmed that the cells isolated from tissues expressed TLR9 mRNA. Therefore, poor CpG-induced IFN responses in PPs were unlikely due to the lack of TLR9 receptor expression (Figure $3 \mathbf{a}$ and $\mathbf{b}$ ).

\section{Role of IL-10 in the regulation of CpG-induced responses in PPs}

Kinetics of IL-10 production in PPs. One factor that could contribute to the reduced $\mathrm{CpG}$ ODN-induced cytokine responses by PP cells could be the presence of immunoregulatory cytokines, such as IL-10. Therefore, we evaluated the kinetics of IL-10 secretion in cultures of JPP and mLN cells, and in PBMCs at different time points following stimulation with CpG ODN. In PBMC and $\mathrm{mLN}$ cultures, significant IL-10 was not detected until after $48 \mathrm{~h}$ of stimulation with CpG ODN (Figure 4a and $\mathbf{c}$ ), whereas in JPP cells, significant IL-10 was detected as early as $16 \mathrm{~h}$ of culture (Figure 4b). Surprisingly, we observed that unstimulated PP cells produced detectable levels of IL-10, whereas in PBMCs detectable IL-10 production occurred only after CpG ODN stimulation (Figure 4d). Therefore, resting PP cells spontaneously secreted IL-10.

IL-10 inhibits CpG-induced IFN $\alpha$ production in PPs. The kinetics of IL-10 production indicated that this cytokine was secreted very early in PP cell cultures. We hypothesized that IL-10 may suppress the induction of IFN $\alpha$ by CpG ODN. Therefore, we evaluated the effect of neutralizing IL-10 with an anti-IL-10 antibody on the CpG-induced IFN $\alpha$ response. The optimal concentration of neutralizing IL-10 antibody was evaluated by a titration experiment, and 1/200 dilution of the antibody was found to be optimal (data not shown). As observed previously, CpG ODN (2429) alone induced lower numbers of IFN $\alpha$-producing cells in IPPs and JPPs compared with PBMCs (Figure 5a-c). However, neutralization of IL-10 resulted in a significant increase in the number of CpG-induced INF $\alpha$-producing cells in IPPs and JPPs (Figure 5a and $\mathbf{b}$ ) but this effect was not significant in PBMCs (Figure 5c). Therefore, IL-10 appears to play a direct role in inhibiting IFN $\alpha$ secretion in PP cells.

\section{CD21 + PP B cells are the major source of IL-10}

We then investigated the phenotype of the predominant cell type in PPs responsible for IL-10 production. As shown before, JPP cells secreted IL-10 regardless of CPG ODN stimulation (Figure 6a), whereas PBMCs secreted IL-10 only after CpG stimulation (Figure 6d). When magnetic activated cell sorting (MACS)-purified CD21 ${ }^{+} \mathrm{B}$ cells from both tissues were stimulated with $\mathrm{CpG}$ ODN, we observed that unstimulated JPP CD21 ${ }^{+} \mathrm{B}$ cells, but not JPP CD21- cells, secreted IL10 (Figure 6b), whereas PBMC CD21 ${ }^{+} \mathrm{B}$ cells did not secrete IL-10, even after CpG ODN or CD40L stimulation (Figure 6e). Induction of IL-10 in PBMCs may require involvement of more than one cell type, as neither of the fractionated PBMC populations $\left(\mathrm{CD} 21^{+}\right.$and $\left.\mathrm{CD} 21^{-}\right)$produced IL-10 (Figure 6d-f).

\section{CD21 + PP B cells inhibit CpG-induced IFN $\alpha$, IFN $\gamma$, and IL-12 responses}

To confirm that $\mathrm{CD} 21^{+} \mathrm{B}$ cells were responsible for the inhibition of the CpG-induced responses in PP, we depleted CD21 ${ }^{+}$ $B$ cells from JPP cells, and using equivalent numbers of cells, we tested the effect of the depletion on CpG-induced responses. As expected, stimulation of JPP cells with CpG ODN resulted in low IFN $\alpha$ responses (Figure 7a). Essentially no IFN $\alpha$ response was detected in $\mathrm{CD} 21^{+} \mathrm{JPP} \mathrm{B}$ cells (Figure 7a). Interestingly, CD21JPP cells had significantly increased IFN $\alpha$ responses (Figure 7a). Similarly, CD21- JPP cells had significantly increased IFN $\gamma$ and IL-12 responses compared with unseparated JPP cells (Figure $7 \mathbf{b}, \mathbf{c}$ ), and again no responses were seen in the $\mathrm{CD} 21^{+} \mathrm{B}$-cell population. These observations suggest that $\mathrm{CD} 21^{+} \mathrm{B}$ cells have a direct role in the inhibition of CpG-induced responses in JPP cells. 

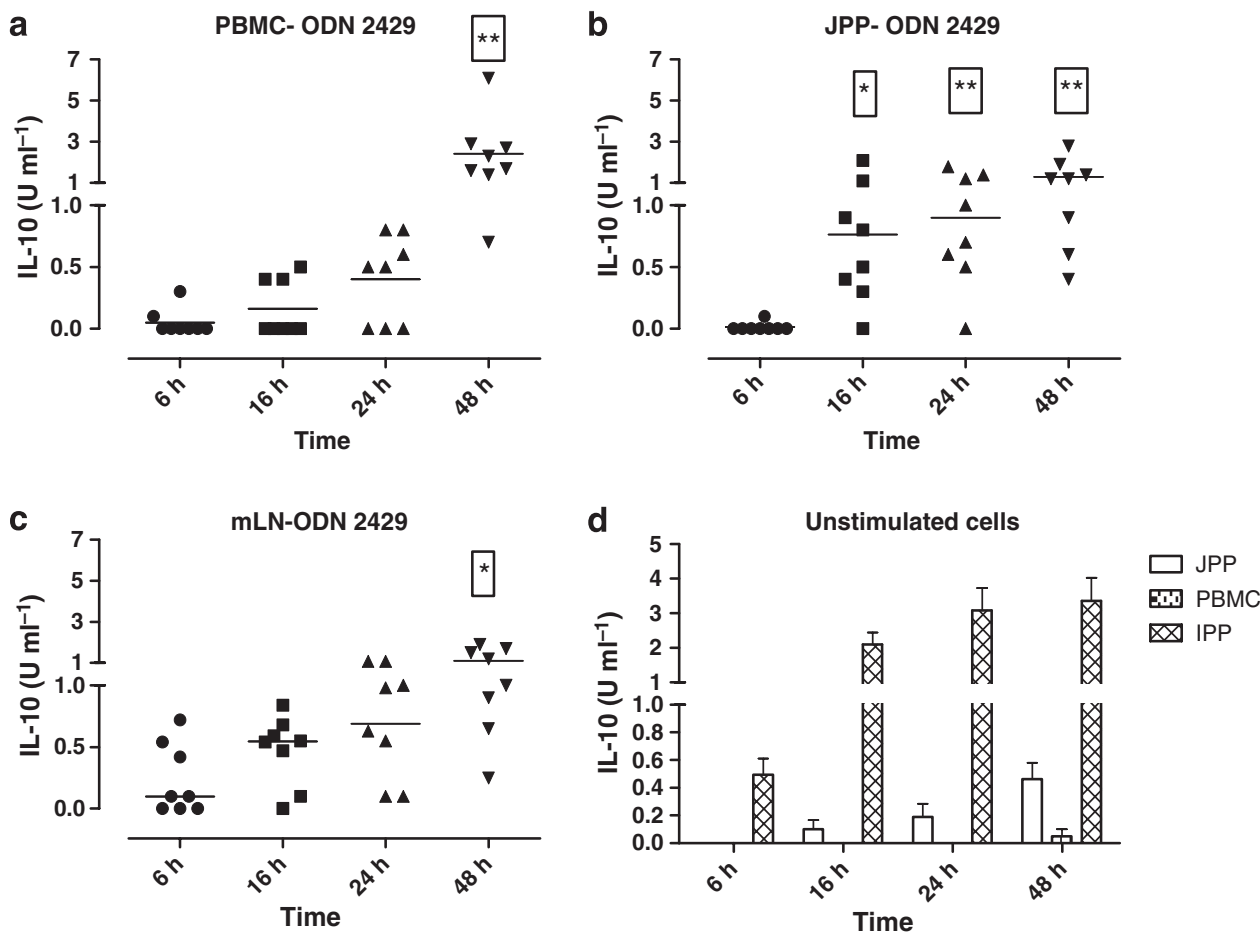

Figure 4 (a-d) Kinetics of IL-10 secretion by PBMCs, JPP, mLN and IPPs stimulated with CpG ODN (2429) or medium alone. Data for individual animals are presented, with mean value indicated by horizontal bar for each treatment group $(n=8)$. Significant difference in IL-10 secretion relative to $6 \mathrm{~h}$ time point is indicated by ${ }^{\star} P<0.1$ and ${ }^{* *} P<0.05$. $\mathrm{U} \mathrm{ml}{ }^{-1}$ for IL-10 was defined previously by Kwong et al., ${ }^{49}$ as the biological activity of IL-10 is represented by one unit being the reciprocal of the dilution that inhibited IFN $\gamma$ by $50 \%$.

Further phenotypic characterization of the PP B cells by flow cytometry showed that the IL-10-secreting B cells were CD21 ${ }^{+}$ $\mathrm{CD}_{2}{ }^{+} \mathrm{CD} 11 \mathrm{c}^{-} \mathrm{CD}_{1} \mathrm{~b}^{-} \mathrm{sIgM}^{-}$(Figure 8).

\section{DISCUSSION}

Our investigations showed that PP CD21+ B cells secrete IL-10, which plays a direct role in the suppression of IFN $\alpha$ secretion by PP cells. Moreover, this B-cell population spontaneously secretes IL-10 in the absence of TLR9 stimulation.

In sheep, $\mathrm{CD} 21^{+} \mathrm{B}$ cells are representative of a naive $\mathrm{B}$-cell population and are mainly $\mathrm{CD}^{-}, \mathrm{CD}_{11} \mathrm{~b}^{-}, \mathrm{CD} 11 \mathrm{c}^{-}$, and CD62L $\mathrm{L}^{+} .27$ They localize in the B-cell follicles of PPs, LNs, and spleen and are actively recirculating in the blood and lymphatic system. ${ }^{28}$ In this study, we found that unstimulated $\mathrm{CD} 72{ }^{+} \mathrm{CD} 11 \mathrm{c}^{-} \mathrm{CD} 21^{+} \mathrm{B}$ cells from PPs secrete a high amount of IL-10, whereas unstimulated CD $72{ }^{+} \mathrm{CD} 11 \mathrm{c}^{-} \mathrm{CD} 21^{+} \mathrm{B}$ cells from blood do not secrete IL-10. This observation suggests that a phenotypically similar B-cell population at a different anatomic location has "acquired" a distinct function. The IL-10-secreting $\mathrm{CD} 21^{+} \mathrm{B}$ cells in PPs may represent a novel population of B cells analogous to the recently proposed $\mathrm{B}_{\text {regs }}{ }^{26}$ Typically, $\mathrm{B}$ cells are known mainly for producing antibodies, but they have the ability to produce cytokines and function as antigen-presenting cells. It is now known that similar to $\mathrm{T}$ cells, the B-cell population consists of distinct subsets capable of performing pathogenic and regulatory functions. ${ }^{26} \mathrm{~B}_{\text {regs }}$ have been observed in several murine models of chronic inflammation, including inflammatory bowel disease, but not in normal intestinal tissue. ${ }^{26}$ One of the mechanism by which $\mathrm{B}_{\text {regs }}$ mediate their regulatory functions is through production of the regulatory cytokines IL-10 and transforming growth factor- $\beta$, which dampen inflammation. ${ }^{29,30}$ Here, we propose a novel B-cell population capable of secreting IL-10 in the steady state and which may perform regulatory functions similar to murine $\mathrm{B}_{\text {regs }}$. However, there appears to be a major difference between the two: the proposed sheep PP $\mathrm{B}_{\text {regs }}$ constitutively occur in normal intestinal tissues in the absence of any known pathology and spontaneously secrete IL-10 in the absence of stimulation. In contrast, murine $\mathrm{B}_{\text {regs }}$ are associated with chronically inflamed intestinal tissue and are not present in steady state. ${ }^{30}$ Further investigations are required to characterize the functions of these sheep $\mathrm{PP}_{\text {regs }}$ in vivo.

Our investigation showed that IL- 10 directly suppressed IFN $\alpha$ responses in PP. IL-10 is an immunoregulatory and anti-inflammatory cytokine. The major known sources of IL-10 are dendritic cells and macrophages. ${ }^{31,32}$ IL-10 can affect a variety of cell types, including monocytes, macrophages, DCs, and neutrophils. It potently inhibits the production of a variety of cytokines (IL-1, IL-6, IL-12, IL-18, and tumor necrosis factor) ${ }^{33,34}$ and chemokines (IL-8, Interferon- $\gamma$ inducible protein-10, Macrophage inflammatory protein- $3 \alpha$, and Regulated upon activation, normal T-expressed, and secreted), $, 35,36$ thereby affecting the recruitment of neutrophils, DCs, and monocytes. IL-10 induces the generation of regulatory $\mathrm{T}$ cells that can suppress antigen-specific responses in vivo and in vitro. ${ }^{37} \mathrm{IL}-10$ also plays an important role in regulating mucosal responses as indicated by numerous studies with IL-10-deficient (IL-10 - / - ) mice that develop spontaneous 

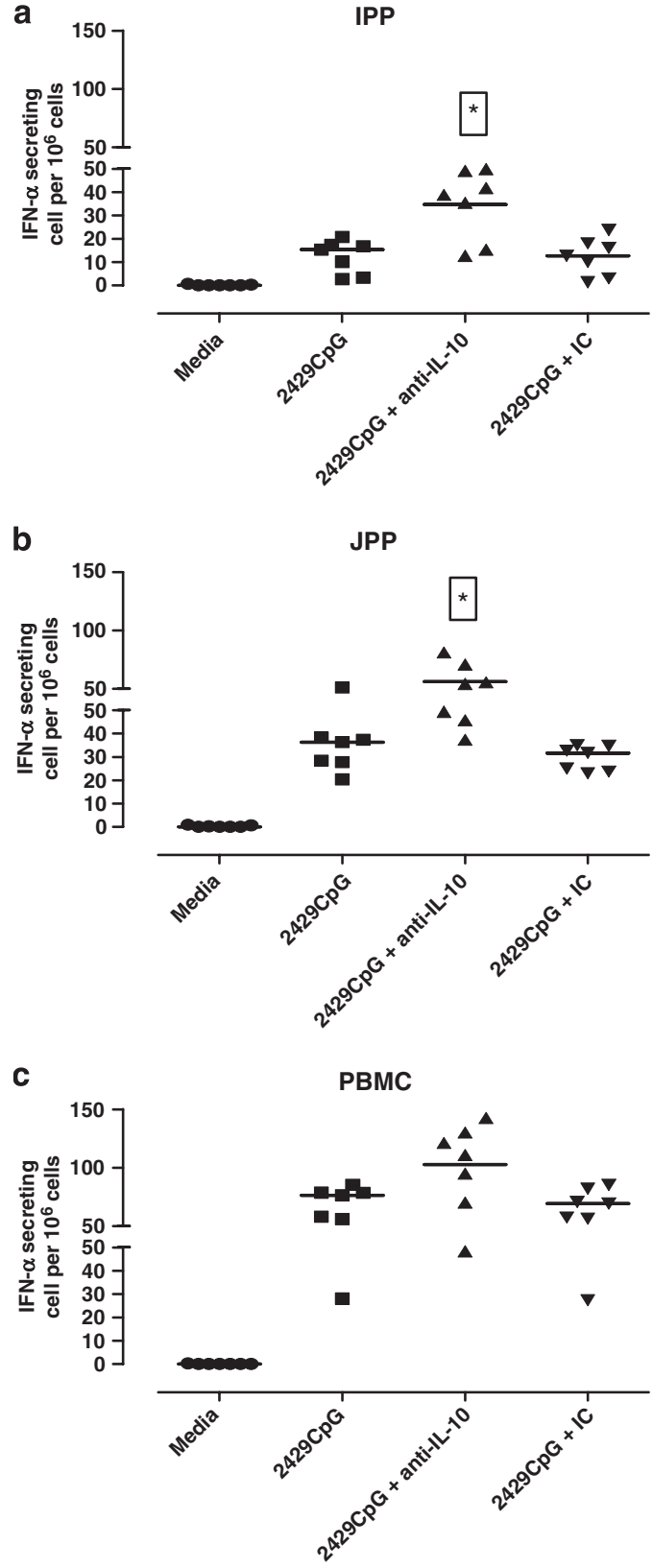

Figure $5 \mathrm{IL}-10$ inhibits $\mathrm{CpG}$-induced IFN $\alpha$ production in PPs. (a-c) IFN $\alpha$ producing cells responses in ovine IPP, JPP and PBMC following stimulation with $2 \mathrm{~g} / \mathrm{ml}$ of CpG ODN (2429) and/or anti-IL-10 antibody $(1 / 200)$ or isotype control antibody (IC) or medium alone. Data for individual animals are presented with mean value indicated by horizontal bar for each treatment group $(n=7)$. Significant differences in IFN $\alpha$-producing cells per million cells relative to $2429 \mathrm{CpG}+\mathrm{IC}$ are indicated by boxed ${ }^{*}(P<0.05)$.

intestinal inflammation..$^{38}$ Our observation that IL-10 inhibited IFN $\alpha$ responses is consistent with Contractor et al. ${ }^{25}$ who showed that IL-10 inhibited IFN $\alpha$ production in spleen $\mathrm{pDCs}$ and also implicated IL-10 in the inability of pDCs from PP to produce IFN $\alpha$, although they did not evaluate the direct effect of IL-10 on PP pDCs. Recently, Monteleone et al. ${ }^{22}$ showed that lamina propria DCs failed to secrete IL-12 in response to CpG and this was attributed to inhibitory IL-10 secreted by these cells, and the authors also showed that unlike spleen or LNC, mucosal DCs expressed high levels of TLR2, 3, 4, 5, and 9 but responded poorly to agonists for these TLRs. ${ }^{22}$ However, this study did not investigate the effect of IL-10 on IFN $\alpha$ secretion in DCs or other cells in PPs.

Interferon- $\alpha$, a type I interferon, is known for its role in antiviral defences, but it can also activate innate and adaptive immune responses. ${ }^{39} \mathrm{IFN} \alpha$, together with IL-12, can induce natural killer cell cytotoxicity and also augment Th1-mediated immunity through innate production of IFN $\gamma$ by natural killer cells and $\mathrm{CD} 8^{+}$cells. IFN $\alpha$ can also act independently of IL- 12 to activate conventional DC ( $\mathrm{cDC}$ ) maturation and cross-presentation and to enhance $\mathrm{CD}^{+}{ }^{+} \mathrm{T}$-cell responses. Therefore, inhibition of IFN $\alpha$ in the PP may skew the balance of immune responses from potentially damaging Th1 type responses.

Jejunal PPs but not IPPs are the primary sites where immune responses are initiated in the gut. ${ }^{24}$ We would therefore expect that cells from PP would respond to a potent immune activator, e.g., CpG ODN, in a manner similar to other secondary lymphoid tissues, such as LNCs. In the present investigations, we show that CpG-induced responses (IFN $\alpha$, IFN $\gamma$, and IL-12) in PPs are reduced compared with lymph nodes and blood. Our observations are in line with others who have reported that DC from lamina propria do not respond to TLR ligands unlike spleen DCs. ${ }^{25}$ These results are not surprising, as the intestine is constantly exposed to bacterial DNA and other PAMPs present in microbial flora and must have mechanisms of preventing unnecessary responses to microbial stimuli. Our findings that cells from PPs respond poorly to $\mathrm{CpG}$ ODN with respect to IFN $\alpha$ and IFN $\gamma$ production despite expressing high levels of TLR9 is consistent with observations by Pedersen et al. ${ }^{40}$ who reported that primary epithelial cells isolated from normal human colon expressed TLR9 mRNA, but were completely unresponsive to CpG-ODN stimulation in vitro. One of the mechanisms that have been proposed for this tolerance is the downregulation of TLR receptors on mucosal immune cells, e.g. TLR4 in lamina propria macrophages. ${ }^{20}$ However, we observed abundant TLR9 mRNA expression in both IPPs and JPPs similar to expression in immune cells from LNs and blood. The TLR9 expression profiles in both IPPs and JPPs and mesenteric LNs in our studies are consistent with the TLR profiles reported recently in sheep ${ }^{18}$ and in pigs. ${ }^{41}$ Taken together, data from our studies and those from others suggest that the low responses of PP cells to CpG ODN were not due to the downregulation of TLR9 receptor. Rather, other mechanisms are involved in downregulating CpGinduced responses.

In sheep and many other species, including humans, two distinct PPs are found in the small intestine, namely JPPs and IPPs, each with their own characteristic development, structure, and function. ${ }^{42}$ IPPs consist of a continuous patch in ovine species, which involutes at a young age and is thought to be responsible for the primary generation of B cells, similar to the bursa of Fabricus in avian species. In contrast, JPPs persist in the adult animal and contain $\mathrm{M}$ cells with clusters of $\mathrm{B}$ cells in the follicleassociated epithelium. ${ }^{42,43}$ The cellular compositions of the PPs are quite different from LNCs and PBMCs. Unlike peripheral LNs, B cells comprise a large proportion of lymphoid cells in 

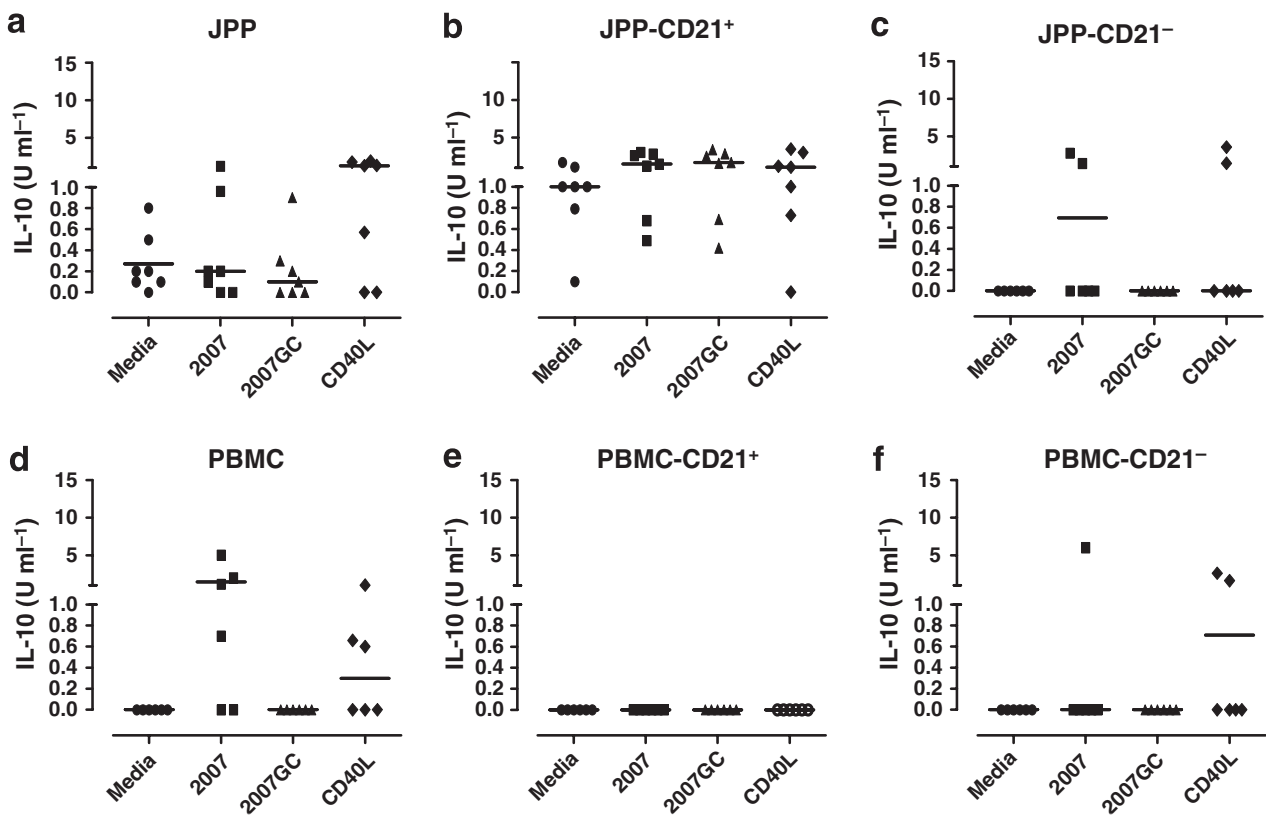

Figure 6 (a-f) MACs-purified CD21 + B cell and CD21- cells obtained from JPP and PBMC were stimulated with either CpG ODN 2007, control GpC 2007, CD40L or medium alone. Data for individual animals are presented and the horizontal bars represent the means of 7 animals.

the PPs (up to $80 \%$ in JPPs and even higher in IPPs) of sheep, ${ }^{43}$ whereas the B-cell frequency in PBMCs or LNCs is around 30$40 \% .{ }^{19}$ In our studies, although the responses in PPs were lower than other lymphoid cells, we showed that JPPs but not IPPs secreted the cytokines IFN $\alpha$, IFN $\gamma$, and IL-12 in response to CpG ODN stimulation. This is consistent with the observation that JPPs but not IPPs are inductive sites for immune responses in the intestine. ${ }^{24}$ We observed significantly higher levels of IL10 secretion in IPP than in JPP cells. This may be due to the higher frequency of B cells in IPPs than JPPs, and as shown, these B cells secrete IL-10. The proportion of CD21 ${ }^{+} \mathrm{B}$ cells in IPP:JPP is 2:1 as assessed by flow cytometry (data not shown). Thus our results suggest that there may be more IL-10-secreting $\mathrm{B}_{\text {regs }}$ in IPPs than JPPs, which may play an important role in the inhibition of innate responses in IPPs.

Interestingly, our results also showed that IL-12 was produced in a similar manner to IFN $\alpha$ in the tested immune tissues (PPs, LNs, and blood) when stimulated with CpG ODN. This observation suggests that IL-12 secretion is also dependent on the frequency of responder cells in the tissues tested. Thus, the CpGresponder cells (presumably "pDC") in the PPs have the ability to produce both significant IFN $\alpha$ and IL-12 similar to previous studies ${ }^{44,45}$ although Contractor et al. ${ }^{25}$ have reported that pDC from mouse PP failed to secrete IL- 12.

The main distinction between our report and other studies focusing on the gut homeostasis and TLR expression is that our study deals with immune cells that are present in PPs. We clearly demonstrated that these PP immune cells were less responsive than their counterpart in other immune compartments. These results suggest that the immune cells in PPs may have regulatory mechanisms to PAMPs independently of IECs. However, we are not excluding the effect of IECs as shown by many studies.
Although IL-10 downregulates IFN $\alpha$ responses, several other factors could also regulate $\mathrm{PP}$ cell responses to $\mathrm{CpG} \mathrm{ODN}$, including (i) additional anti-inflammatory cytokines, such as transforming growth factor- $\beta$ and thymic stromal lymphopoietin contributing to the anti-inflammatory environment; (ii) multiple signals may be required to induce optimal innate immune responses (e.g., multiple TLR, BCR engagement, T-cell and myeloid DC cooperation); (iii) T-regulatory cells working in concert with B-regulatory cells in the intestine to modulate immune responses. However, further investigations are required to determine the mechanisms by which PP disregard PAMPs from commensal microorganisms but induce an immune response to pathogens.

In conclusion, this analysis showed that PP B cells spontaneously secrete IL-10, which "conditions" an anti-inflammatory environment in this tissue leading to poor cytokine responses to TLR9 agonist, CpG ODN. This may represent a strategy by which PPs dampen innate responses to PAMPs in intestinal immune tissues to maintain intestinal immune homeostasis.

\section{METHODS}

\section{Oligodeoxynucleotides}

A-class (2216), B-class (2007), and C-class (2429) CpG ODN (Table 1) have been shown previously to be biologically active in sheep PBMCs and LN cells in vitro and in vivo. ${ }^{19} \mathrm{CpG}$ ODN sequences 2007, 2216, and 2336 were obtained from Merial Limited (Lyon, France), CpG ODN 2429 from Coley Pharmaceutical Group (Wellesley, MA), and control non-CpG ODNs 2007GC and 2216GC were purchased from Operon (Alameda, CA).

Animals. Suffolk sheep of either sex (3-4 months of age) were obtained from the Department of Poultry and Animal Science (University of Saskatchewan, Saskatoon, SK). Experimental protocols were approved by the University of Saskatchewan Animal Care Committee and animals were housed in the same pen throughout each experiment. 

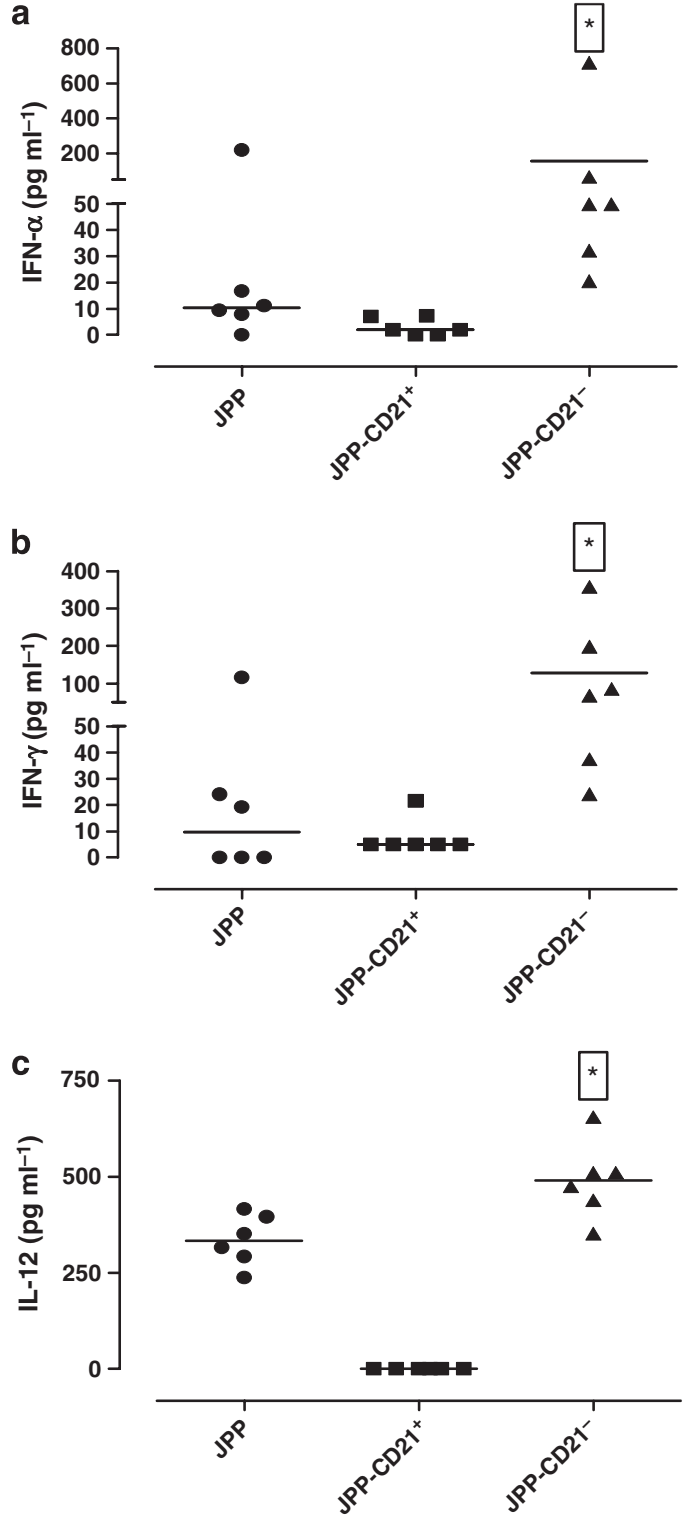

Figure $7 \mathrm{CD} 21^{+}$PP B cells inhibit CpG-induced IFN $\alpha$, IFN $\gamma$ and IL-12 responses. (a-c) MACS-purified CD21+ $\mathrm{B}$ cells and CD21- cell populations from JPPs were stimulated with CpG ODN 2429. The levels of IFN $\alpha$, IFN $\gamma$, and IL-12 were assayed in culture supernatants by enzyme-linked immunosorbent assay. Data for individual animals are presented and the horizontal bars represent the mean of six animals.

Isolation of PBMCs, JPPs, IPPs, and LN cells. Blood was collected from the jugular vein of sheep in ethylene diamine tetra-acetic acid-treated VACUTAINER tubes (Becton Dickinson and Company, Mountain View, CA) and PBMCs were isolated using 54\% isotonic PERCOLL (GE Healthcare AB, Piscataway, NJ), as described previously. ${ }^{46}$

Sheeps were euthanized and JPPs, IPPs, and scLNs, and mLNs were removed and placed in ice-cold minimum essential medium (MEM, Gibco BRL, Carlsbad, CA) containing the antibiotics $100 \mathrm{IU} \mathrm{ml}^{-1}$ penicillin, $100 \mathrm{\mu g} \mathrm{ml}^{-1}$ streptomycin sulfate, and $0.25 \mathrm{\mu g} \mathrm{ml}^{-1}$ Amphotericin B (Sigma-Aldrich, St Louis, MO). Cells were isolated from LNs by finely mincing tissue with a scalpel, filtering the cell suspension through a $40-\mu \mathrm{m}$ nylon cell strainer (Becton Dickinson Labware, Franklin Lakes, NJ), and washing the cells with Dulbecco's phosphate-buffered saline (PBSA) ( $\mathrm{pH} 7.2$ ), as described previously. ${ }^{24}$
IPP and JPP cells were also isolated from the same sheep as described previously. ${ }^{24,47}$ Cells were resuspended in AIM-V medium containing $2 \%$ fetal bovine serum.

Tissue culture conditions. Stimulation of PBMCs, JPPs, IPPs, and LN cells was performed in 96-well, round-bottomed plates (Nunc, Naperville, IL) using AIM-V medium (Invitrogen, Carlsbad, CA) supplemented with $2 \%$ fetal bovine serum, $100 \mathrm{IU} \mathrm{ml}^{-1}$ penicillin, $100 \mu \mathrm{g} \mathrm{ml}^{-1}$ streptomycin sulfate, $0.25 \mu \mathrm{g} \mathrm{ml}^{-1}$ Amphotericin B, $2 \mathrm{~mm}$ L-glutamine, $50 \mu \mathrm{M} 2$-mercaptoethanol, and $10 \mu \mathrm{g} \mathrm{ml}^{-1}$ polymyxin B sulfate (Sigma-Aldrich). For each treatment, $5 \times 10^{5}$ cells (PBMCs, JPPs, IPPs, and LNs) were cultured in triplicate wells in $200 \mu \mathrm{l}$ total volume for $48 \mathrm{~h}$ at $37^{\circ} \mathrm{C}$ in an atmosphere of $5 \% \mathrm{CO}_{2}$ and $95 \%$ humidity. Culture supernatants were harvested and stored at $-20^{\circ} \mathrm{C}$. For $\mathrm{CD} 21^{-}$cells, $3 \times 10^{5}$ cells were cultured with $\mathrm{CpG}$ ODN or alone in triplicate wells in $200 \mu \mathrm{l}$ total volume.

ELISA for IFN- $\alpha$, IFN- $\gamma$, IL-10, and IL-12. The IFN- $\alpha$, IFN- $\gamma$, IL-10, and IL-12 enzyme-linked immunosorbent assays used in these studies were shown previously to detect ovine and bovine IFN- $\alpha$, IFN- $\gamma$, and IL-12 cytokines as described elsewhere. ${ }^{46,48,49}$

IFN $\alpha$ enzyme-linked immunosorbent spot assay and neutralization of IL-10. Interferon- $\alpha$-secreting cells were detected using an enzyme-linked immunosorbent spot assay. Microtiter nitrocellulose filtration plates (Whatman, Clifton, NJ) were coated overnight with two monoclonal mouse anti-bovine IFN- $\alpha$ antibodies (clones IFN-1C6 and IFN-1D10) and were both diluted to 1:1,000. Cultures were incubated for $24 \mathrm{~h}$ at $37^{\circ} \mathrm{C}$ in a humidified atmosphere with $5 \% \mathrm{CO}_{2}$ before removing the cells. Total IFN $\alpha$-secreting cells were detected by first adding biotinylated goat anti-rabbit IgG ( $\mathrm{H}+\mathrm{L}$ chain specific; 1:5,000 dilution; Zymed, South San Fransisco, CA), followed by alkaline phosphatase-conjugated streptavidin (1:1,000 dilution; Jackson Immunoresearch Laboraties, Westgrove, PA), and finally IFN $\alpha$-secreting cells were visualized with 5-bromo-4-chloro3-indolyl phosphate/nitroblue tetrazolium insoluble alkaline phosphatase substrate (Sigma-Aldrich). Data presented are mean values for replicate samples. To inhibit the action of IL-10, neutralizing mouse anti-bovine IL-10 antibody (Serotec, MCA 2111EL) was added at 1/200 dilution with CpG ODN to cell cultures.

Magnetic activated cell sorting. The $\mathrm{CD} 21^{+} \mathrm{B}$-cell fraction was isolated as described previously. ${ }^{50}$ Briefly, JPPs and PBMCs were stained with mouse anti-bovine antibody (IgG1, AbD Serotec, UK) for $15 \mathrm{~min}$ at $4^{\circ} \mathrm{C}$. The cells were then washed twice with MACS buffer (PBSA, ethylene diamine tetra-acetic acid and 10\% BSA) and followed by centrifugation for $8 \mathrm{~min}$ at $440 \mathrm{~g}$. The cells were then stained with goat anti-mouse IgG1 phycoerythrin conjugate (Southern Biotech, Birmingham, AL) for $15 \mathrm{~min}$ at $4^{\circ} \mathrm{C}$ and wash as above. The cells were labeled with antiphycoerythrin magnetic beads for $15 \mathrm{~min}$ at $4^{\circ} \mathrm{C}$ and eluted through the LC MACS column (Miltenyi Biotec, Bergish Gladbach, Germany) according to the manufacturer's instruction. The CD21+ B-cell fraction was eluted, washed in PBSA and resuspended in AIM-V media containing $2 \%$ fetal bovine serum.

Quantitative RT-PCR. Reverse transcrition-PCR was used to quantify TLR9 mRNA in IPPs, JPPs, mLNs, jejunum (small intestine in interspaces between PPs), duodenum, and colon. TLR9 mRNA was also assessed in single-cell suspensions from these tissues (IPPs, JPPs, mLNs, and PBMCs). Total RNA was isolated from all tissues and isolated cell suspensions using TRIZOL reagent (Molecular Research Center, Cincinnati, OH) and DNAse I Amp Grade (Invitrogen). For complementary DNA (cDNA), RNA $(1 \mu \mathrm{g})$ was incubated in a final volume of $15 \mu \mathrm{l}$ with dNTP, oligo dT, RNASEOUT inhibitor (Invitrogen), buffer RT, and SUPERSCRIPT reverse transcriptase (Invitrogen). The reaction was performed according to the manufacturer's recommendations. The cDNA generated was either used immediately for qPCR or stored at $-80^{\circ} \mathrm{C}$. 


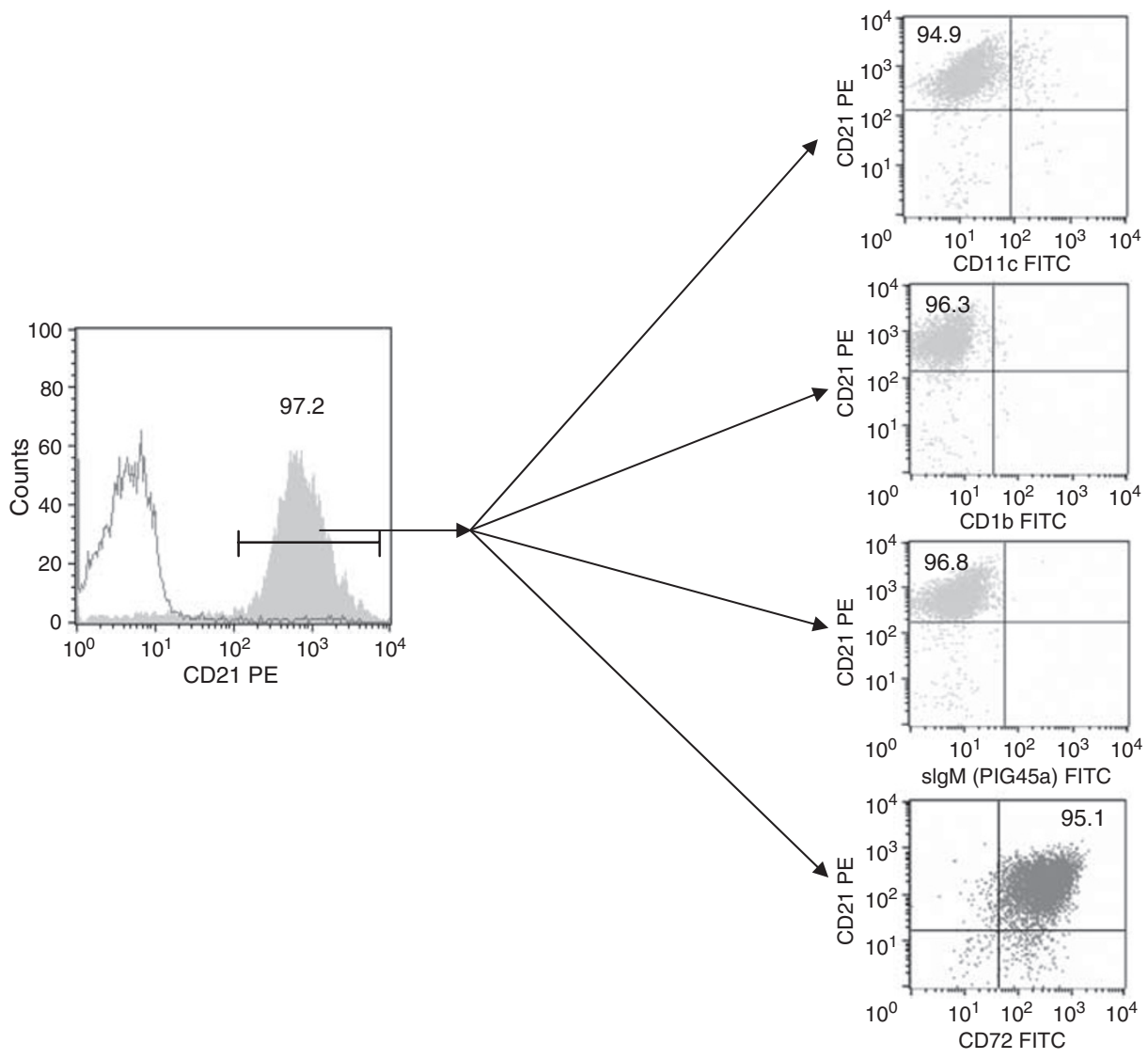

Figure 8 Characterization of PP B-regulatory cells by flow cytometry. Data show purified JPP CD $21^{+}$B cells ( $97.2 \%$ purity), which has been gated to discriminate doublet cells and dead cells. Each CD21+ B cells are double-labeled with CD11c, CD1b, CD72, and slgM mAbs and conjugated with isotype-specific fluorescein isothiocyanate FITC antibody.

Table 1 A, B and C-class CpG ODN sequences and backbone structure

\begin{tabular}{lcl}
\hline ODN name & Class & Sequence \\
\hline 2007 & B & tcgtcgttgtcgtttgtcgtt \\
$2007 G C$ & B & tgctgcttgtgcttttgtgctt \\
2216 & A & ggGGGACGATCGTCggggg \\
$2216 G C$ & A & ggGGGAGCATGCTGggggg \\
2336 & A & ggGGACGACGTCGTGGggggg \\
2429 & C & tcgtcgtttcggcggccgccg \\
\hline
\end{tabular}

Lower case: phosphorothioate backbone.

Upper case: phosphodiester backbone.

Complementary DNA was combined with primer/probe sets and IQ SYBR Green Supermix (Molecular Probes) according to the manufacturer's recommendations. All primers were designed using Clone Manager (Scientific and Educational Software, Cary, NC). TLR9 forward primer 5'CGTGAGCAGCAACAGCATC 3' and reverse primer 5'TAAGCGACCGAACCAGAAGG 3' were purchased from SigmaAldrich. The PCR conditions were $95^{\circ} \mathrm{C}$ for $3 \mathrm{~min}$, followed by 45 cycles with denaturation at $95^{\circ} \mathrm{C}$ for $15 \mathrm{~s}$, annealing temperature at $59^{\circ} \mathrm{C}$ for $30 \mathrm{~s}$, and elongation at $72^{\circ} \mathrm{C}$ for $30 \mathrm{~s}$. Real-time assays were run on a Bio-Rad ICYCLER IQ system (Bio-Rad Laboratories, Hercules, CA). The specificity of the PCRs was assessed by the analysis of the melting curves of the products and size verification and sequencing of the amplicons.
To normalize the amount of cDNA, we sampled equal tissue sizes, quantitated RNA, assessed its quality before reverse transcription, and used a reference gene. Samples were normalized internally using the average cycle threshold $\left(C_{t}\right)$ of glyceraldehyde-3-phosphate dehydrogenase as a reference in each tissue. To quantify the numbers of copies, plasmid containing sheep TLR9 cDNA were linearized with XhoI (New England Biolabs) and 10 twofold dilutions of the plasmid were used to create a standard curve for the quantification of the RNA-generated cDNA. Values were expressed as transcript copy number per $1 \mu \mathrm{g}$ of total input RNA, which were determined in each sample by interpolation with the respective standard curves. The correlation coefficient of TLR9 standard curve was 0.996 . The concentration of the test samples was calculated from the standard curves, according to the formula $y=-M C_{t}+B$, where $M$ is the slope of the curve, $C_{t}$ is the point during the exponential phase of amplification in which the fluorescent signal is first recorded as being statistically significant above background, and $B$ is the $y$ axis intercept. Only $C_{\mathrm{t}}$ values $<40$ were used for calculation of the PCR efficiency from the given slope according to the equation: PCR efficiency $=\left(10^{[1 / M]} 1\right) \times 100$. All PCRs showed efficiency between 94 and $100 \%$.

Flow cytometry. Monoclonal antibody specific for sheep CD1b (MCA 1646) and CD21 (MCA1424G) were purchased from Serotec and $\operatorname{IgM}$ (PIg45A), and CD11c (BAQ153A) were purchased from VMRD (Pullman, WA). CD72 (DU2-104) was produced from hybridomas in house. Fluorescein isothiocyanate-conjugated and phycoerythrin-conjugated, isotype-specific anti-mouse immunoglobulin (Ig) was purchased from Cedarlane Laboratories (Burlington, ON, Canada). Phenotypic analysis was restricted to viable cells, and the level of specific monoclonal 
antibody ( $\mathrm{mAb}$ ) binding was quantified by substracting cells that reacted with isotype match, irrelevant $\mathrm{mAb}$ (Cedarlane Laboratories). Irrelevant $\mathrm{mAbs}$ were used at the same concentration $\left(1-10 \mu \mathrm{g} \mathrm{ml}^{-1}\right)$ as relevant $\mathrm{mAb}$. Data acquisition and analysis were performed with a FAC-Scan (Becton-Dickinson, Mountain View, CA) flow cytometry and Cell Quest program.

Statistical analysis Data were analyzed using the statistical software program GRAPHPAD PRISM 5 (Graphpad Software, San Diego, CA). One-way ANOVA (Kruskal-Wallis) and Dunn's multiple comparison tests were performed on each treatment and tissue. Differences were considered significant when $P<0.05$.

\section{ACKNOWLEDGMENTS}

We thank Dr Kuldip Mirakhur, Sherry Tetland and Lucas Wirth for assistance with care and management of animals. We also thank Ponn Benjamin and Donna Dent for technical assistance. Financial support was provided by grants from Natural Science and Engineering Research Council (NSERC), National Institutes of Health (NIH U01 Al057264-01), and Merial Limited. This article is published with the permission of the director of VIDO as journal series no. 518 .

\section{DISCLOSURE}

The authors declared no conflict of interest.

(c) 2009 Society for Mucosal Immunology

\section{REFERENCES}

1. Medzhitov, R. Toll-like receptors and innate immunity. Nat. Rev. Immunol. 1, 135-145 (2001).

2. Takeda, K., Kaisho, T. \& Akira, S. Toll-like receptors. Annu. Rev. Immunol. 21, 335-376 (2003).

3. Poltorak, A. et al. Defective LPS signaling in $\mathrm{C} 3 \mathrm{H} / \mathrm{HeJ}$ and C57BL/10ScCr mice: mutations in Tlr4 gene. Science 282, 2085-2088 (1998).

4. Alexopoulou, L., Holt, A.C., Medzhitov, R. \& Flavell, R.A. Recognition of double-stranded RNA and activation of NF-kappaB by Toll-like receptor 3 . Nature 413, 732-738 (2001)

5. Jurk, M. et al. Human TLR7 or TLR8 independently confer responsiveness to the antiviral compound R-848. Nat. Immunol. 3, 499 (2002).

6. Hemmi, H. et al. A Toll-like receptor recognizes bacterial DNA. Nature 408, 740-745 (2000).

7. Krieg, A.M. \& Wagner, H. Causing a commotion in the blood: immunotherapy progresses from bacteria to bacterial DNA. Immunol. Today 21, 521-526 (2000).

8. Kamstrup, S., Verthelyi, D. \& Klinman, D.M. Response of porcine peripheral blood mononuclear cells to $\mathrm{CpG}$-containing oligodeoxynucleotides. Vet. Microbiol. 78, 353-362 (2001).

9. Jorgensen, J.B., Johansen, A., Stenersen, B. \& Sommer, A.I. CpG oligodeoxynucleotides and plasmid DNA stimulate Atlantic salmon (Salmo salar L.) leucocytes to produce supernatants with antiviral activity. Dev. Comp. Immunol. 25, 313-321 (2001).

10. Verthelyi, D. \& Klinman, D.M. Immunoregulatory activity of CpG oligonucleotides in humans and nonhuman primates. Clin. Immunol. 109, 64-71 (2003).

11. Wernette, C.M., Smith, B.F., Barksdale, Z.L., Hecker, R. \& Baker, H.J. CpG oligodeoxynucleotides stimulate canine and feline immune cell proliferation. Vet. Immunol. Immunopathol. 84, 223-236 (2002).

12. Zhang, Y. et al. Induction of interleukin- 6 and interleukin-12 in bovine $B$ lymphocytes, monocytes, and macrophages by a $\mathrm{CpG}$ oligodeoxynucleotide (ODN 2059) containing the GTCGTT motif. J. Interferon. Cytokine Res. 21, 871-881 (2001).

13. Liu, Y.J. IPC: professional type 1 interferon-producing cells and plasmacytoid dendritic cell precursors. Annu. Rev. Immunol. 23, 275-306 (2005).

14. Lee, J., Mo, J.H., Shen, C., Rucker, A.N. \& Raz, E. Toll-like receptor signaling in intestinal epithelial cells contributes to colonic homoeostasis. Curr. Opin. Gastroenterol. 23, 27-31 (2007)

15. Matsushima, H., Yamada, N., Matsue, H. \& Shimada, S. TLR3-, TLR7-, and TLR9-mediated production of proinflammatory cytokines and chemokines from murine connective tissue type skin-derived mast cells but not from bone marrow-derived mast cells. J. Immunol. 173, 531-541 (2004).
16. Kabelitz, D. Expression and function of Toll-like receptors in $T$ Iymphocytes. Curr. Opin. Immunol. 19, 39-45 (2007).

17. Li, J. et al. CpG DNA-mediated immune response in pulmonary endothelial cells. Am. J. Physiol. Lung Cell Mol. Physiol. 287, L552-L558 (2004).

18. Menzies, M. \& Ingham, A. Identification and expression of Toll-like receptors $1-10$ in selected bovine and ovine tissues. Vet. Immunol. Immunopathol. 109, 23-30 (2006).

19. Booth, J.S. et al. Innate immune responses induced by classes of $\mathrm{CpG}$ oligodeoxynucleotides in ovine lymph node and blood mononuclear cells. Vet. Immunol. Immunopathol. 115, 24-34 (2007).

20. Smith, P.D. et al. Intestinal macrophages lack CD14 and CD89 and consequently are down-regulated for LPS- and IgA-mediated activities. J. Immunol. 167, 2651-2656 (2001).

21. Smythies, L.E. et al. Human intestinal macrophages display profound inflammatory anergy despite avid phagocytic and bacteriocidal activity. J. Clin. Invest. 115, 66-75 (2005).

22. Monteleone, I., Platt, A.M., Jaensson, E., Agace, W.W. \& Mowat, A.M. IL-10-dependent partial refractoriness to Toll-like receptor stimulation modulates gut mucosal dendritic cell function. Eur. J. Immunol. 38, 1533-1547 (2008)

23. Neish, A.S. et al. Prokaryotic regulation of epithelial responses by inhibition of IkappaB-alpha ubiquitination. Science 289, 1560-1563 (2000).

24. Mutwiri, G. et al. Ileal and jejunal Peyer's patches play distinct roles in mucosal immunity of sheep. Immunology 97, 455-461 (1999).

25. Contractor, N., Louten, J., Kim, L., Biron, C.A. \& Kelsall, B.L. Cutting edge: Peyer's patch plasmacytoid dendritic cells (pDCs) produce low levels of type i interferons - possible role for IL-10, TGFbeta, and prostaglandin E2 in conditioning a unique mucosal pDC phenotype. J. Immunol. 179, 2690-2694 (2007)

26. Mizoguchi, A. \& Bhan, A.K. A case for regulatory B cells. J. Immunol. 176, 705-710 (2006).

27. Young, A.J., Dudler, L., Yamaguchi, K., Marston, W. \& Hein, W.R. Structure and expression of ovine complement receptor type 2. Vet. Immunol. Immunopathol. 72, 67-72 (1999).

28. Gupta, V.K., McConnell, I., Dalziel, R.G. \& Hopkins, J. Two B cell subpopulations have distinct recirculation characteristics. Eur. J. Immunol. 28, 1597-1603 (1998)

29. Gonnella, P.A., Waldner, H.P. \& Weiner, H.L. B cell-deficient (mu MT) mice have alterations in the cytokine microenvironment of the gut-associated lymphoid tissue (GALT) and a defect in the low dose mechanism of oral tolerance. J. Immunol. 166, 4456-4464 (2001).

30. Mizoguchi, A., Mizoguchi, E., Takedatsu, H., Blumberg, R.S. \& Bhan, A.K. Chronic intestinal inflammatory condition generates IL-10-producing regulatory B cell subset characterized by CD1d upregulation. Immunity 16, 219-230 (2002).

31. Iwasaki, A. \& Kelsall, B.L. Freshly isolated Peyer's patch, but not spleen, dendritic cells produce interleukin 10 and induce the differentiation of Thelper type 2 cells. J. Exp. Med. 190, 229-239 (1999).

32. Boonstra, A. et al. Macrophages and myeloid dendritic cells, but not plasmacytoid dendritic cells, produce IL-10 in response to MyD88- and TRIF-dependent TLR signals, and TLR-independent signals. J. Immunol. 177, 7551-7558 (2006).

33. D'Andrea, A. et al. Interleukin 10 (IL-10) inhibits human lymphocyte interferon gamma-production by suppressing natural killer cell stimulatory factor/L-12 synthesis in accessory cells. J. Exp. Med. 178, 1041-1048 (1993).

34. de Waal Malefyt, R., Abrams, J., Bennett, B., Figdor, C.G. \& de Vries, J.E. Interleukin 10(IL-10) inhibits cytokine synthesis by human monocytes: an autoregulatory role of IL-10 produced by monocytes. J. Exp. Med. 174, 1209-1220 (1991)

35. Berkman, N. et al. Inhibition of macrophage inflammatory protein-1 alpha expression by IL-10. Differential sensitivities in human blood monocytes and alveolar macrophages. J. Immunol. 155, 4412-4418 (1995).

36. Marfaing-Koka, A., Maravic, M., Humbert, M., Galanaud, P. \& Emilie, D. Contrasting effects of IL-4, IL-10 and corticosteroids on RANTES production by human monocytes. Int. Immunol. 8, 1587-1594 (1996).

37. Asseman, C., Mauze, S., Leach, M.W., Coffman, R.L. \& Powrie, F. An essential role for interleukin 10 in the function of regulatory $T$ cells that inhibit intestinal inflammation. J. Exp. Med. 190, 995-1004 (1999). 
38. Kuhn, R., Lohler, J., Rennick, D., Rajewsky, K. \& Muller, W. Interleukin-1 0-deficient mice develop chronic enterocolitis. Cell 75, 263-274 (1993).

39. Colonna, M., Trinchieri, G. \& Liu, Y.J. Plasmacytoid dendritic cells in immunity. Nat. Immunol. 5, 1219-1226 (2004).

40. Pedersen, G., Andresen, L., Matthiessen, M.W., Rask-Madsen, J. \& Brynskov, J. Expression of Toll-like receptor 9 and response to bacterial CpG oligodeoxynucleotides in human intestinal epithelium. Clin. Exp. Immunol. 141, 298-306 (2005).

41. Shimosato, T. et al. Swine Toll-like receptor 9(1) recognizes CpG motifs of human cell stimulant. Biochim. Biophys. Acta. 1627, 56-61 (2003).

42. Landsverk, T. et al. The intestinal habitat for organized lymphoid tissues in ruminants; comparative aspects of structure, function and development. Vet. Immunol. Immunopathol. 28, 1-16 (1991).

43. Griebel, P.J. \& Hein, W.R. Expanding the role of Peyer's patches in B-cell ontogeny. Immunol. Today 17, 30-39 (1996).

44. Bilsborough, J., George, T.C., Norment, A. \& Viney, J.L. Mucosal CD8alpha+ DC, with a plasmacytoid phenotype, induce differentiation and support function of T cells with regulatory properties. Immunology 108, 481-492 (2003)

45. Castellaneta, A., Abe, M., Morelli, A.E. \& Thomson, A.W. Identification and characterization of intestinal Peyer's patch interferon-alpha producing (plasmacytoid) dendritic cells. Hum. Immunol. 65, 104-113 (2004).

46. Mena, A. et al. Innate immune responses induced by CpG oligodeoxyribonucleotide stimulation of ovine blood mononuclear cells. Immunology 110, 250-257 (2003).

47. Griebel, P.J. Isolation of lymphoid follicles from Peyer's patches. Immunol. Methods Manual 3, 2079 (1997).

48. Hope, J.C. et al. Development of detection methods for ruminant interleukin (IL)-12. J. Immunol. Methods 266, 117-126 (2002).

49. Kwong, L.S. et al. Development of an ELISA for bovine IL-10. Vet. Immunol. Immunopathol. 85, 213-223 (2002).

50. Pintaric, M., Gerner, W. \& Saalmuller, A. Synergistic effects of IL-2, IL-12 and IL-18 on cytolytic activity, perforin expression and IFN-gamma production of porcine natural killer cells. Vet. Immunol. Immunopathol. $121,68-82(2008)$ 